\title{
LA CONSECUCIÓN DE LA ALFABETIZACIÓN UNIVERSAL EN EL ALTO NERVIÓN (PAÍS VASCO)
}

\author{
The achievement of the universal literacy in the High Nervion \\ (Basque Country)
}

\author{
Aketza Merino Zulueta ${ }^{\alpha}$ \\ Fecha de recepción: 11/04/2018 • Fecha de aceptación: 19/10/2018
}

Resumen. El objetivo del presente trabajo consiste en realizar un estudio de caso concreto acerca del proceso de alfabetización en la comarca vasca del Alto Nervión, entre Araba/Álava y Bizkaia. Basándose en la necesidad de huir de generalizaciones y resaltar matices, valoramos los avances de esta comarca con relación al calendario marcado por otras zonas próximas, otras provincias o España en su conjunto, en el contexto de los estudios que analizan las capacidades alfabetizadoras como elemento esencial para la mejora del capital humano, factor necesario aunque no suficiente para el desarrollo económico, reflexión a la que se dedica la primera parte del trabajo. A continuación se realiza un recorrido que abarca desde los primeros datos sobre alfabetización que aparecen a mediados del siglo XIX, hasta 1935, momento en que la comarca ya ha alcanzado la alfabetización universal, pasando por una fase intermedia protagonizada por una importante crisis económica y demográfica. El estudio se lleva a cabo mediante fuentes estadísticas como son los padrones municipales de población que reflejan la adquisición por parte de cada individuo de las capacidades de leer y escribir. El análisis nos lleva a concluir que el proceso de alfabetización, a pesar de enfrentar importantes desequilibrios territoriales, de género o socioprofesionales, se había completado ya antes de la Guerra Civil, capacitando a su capital humano para el desarrollo económico que el Alto Nervión estaba emprendiendo.

Palabras clave: Alfabetización; Capital humano; Educación; País Vasco; Desarrollo.

\footnotetext{
${ }^{\alpha}$ Departamento de Historia Contemporánea. Facultad de Ciencias Sociales y de la Comunicación. Universidad del País Vasco. Sarriena Auzoa, s/n, 48940 Leioa (Bizkaia). España. aketzamerino@ gmail.com
}

Cómo citar este artículo: Merino Zulueta, Aketza. «La consecución de la alfabetización universal en el Alto Nervión (País Vasco)». Historia y Memoria de la Educación 10 (2019): 525-564 
Abstract: The aim of this article is to study a concrete example of the literacy process in the Basque region of High Nervión, located between Araba/Álava and Bizkaia. In order to avoid generalizations and to highlight nuances, in the article we evaluate the achievements of the region by means of a comparison with other nearby areas as well as the rest of Spain. We go about our comparison in the context of studies based on the analysis of the access to the basic education as a way of improving human capital, education being a necessary factor but not in itself enough to initiate economic development. This aspect is dealt with in the first part of the work. Secondly, we will move from the first information on literacy that appears in the middle of the 19th century forward to 1935, just before the Spanish Civil War, when the High Nervion had recently achieved full literacy of all of its inhabitants. This occurred after a phase characterized by an economic and demographic crisis. The study was carried out on the basis of statistical sources such as municipal registers of inhabitants, in which the literacy skills of each person are noted. In the end we conclude that, despite important differences between territories, genders and labor situations, the literacy process was completed before the Civil War, enabling and empowering the human capital of the High Nervion's for the economic development that the region was initiating.

Keywords: Literacy; Human capital; Education; Basque Country; Development.

\section{INTRODUCCIÓN}

El Alto Nervión es una comarca a caballo entre las provincias vascas de Araba/Álava y Bizkaia situada en la cabecera del río del mismo nombre, que desemboca en la Ría de Bilbao. Está comprendida por los actuales municipios alaveses de Laudio/Llodio, Amurrio (al que pertenecen Lezama y Arrastaria, ayuntamientos que no fueron anexionados a aquel hasta 1976), Ayala/Aiara, Artziniega y Okondo, así como el vizcaíno de Urduña/Orduña. 


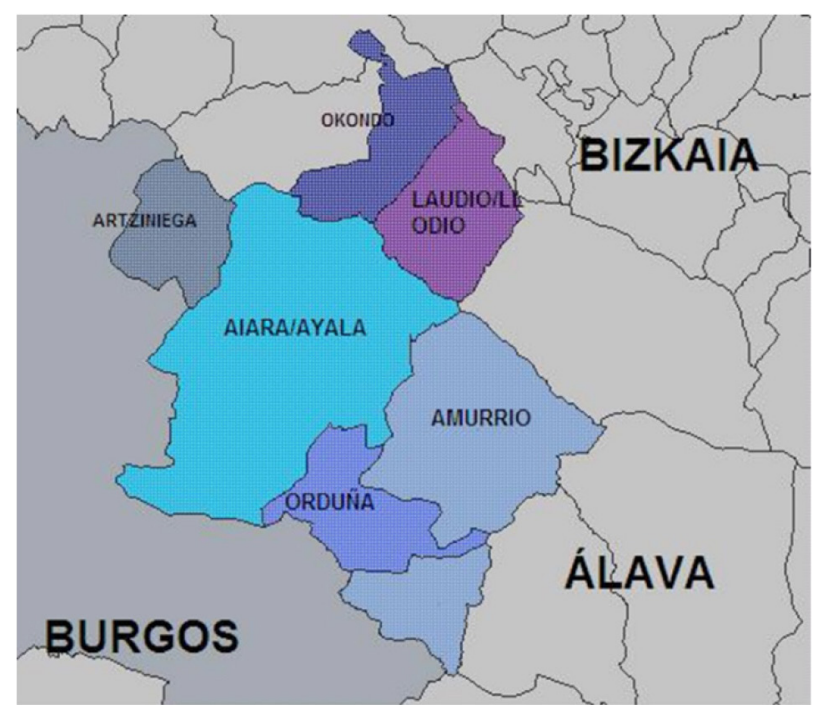

Mapa 1. El Alto Nervión

Además de constituir una unidad geográfica coherente y compartir en gran medida su trayectoria histórica e institucional, a mediados del siglo XIX el Alto Nervión presentaba unos comportamientos sociodemográficos homogéneos, diferenciados de los de otras regiones próximas quizá con la salvedad de las Encartaciones vizcaínas. ${ }^{1}$ Por aquel entonces, era una comarca fundamentalmente rural con un importante pasado ferrón que era poco más que recuerdo, aunque es de notar sin embargo que albergaba un importante enclave en el comercio del norte peninsular como era Urduña/Orduña, en la principal ruta que conectaba el puerto de Bilbao con la meseta castellana. ${ }^{2}$ Los comienzos de las explotaciones mineras y la industrialización de la Ría de Bilbao, junto al establecimiento de la vía férrea Bilbao-Castejón atravesando la comarca, provocaron un importante éxodo rural en el Alto Nervión al mismo tiempo que sus activos económicos se derrumbaban. Todo ello provocó una larga fase de crisis que duró medio siglo hasta que experimentó una tímida primera industrialización a partir de los años veinte del siglo

\footnotetext{
${ }^{1}$ Manuel González Portilla y José Urrutikoetxea Lizarraga, Vivir en familia, organizar la sociedad: familia y modelos familiares, las provincias vascas a las puertas de la modernización (1860) (Bilbao: Servicio Editorial de la UPV-EHU, 2003), 575-640.

2 Ana María Canales Cano, Orduña: estudio histórico-artístico (Bilbao: Diputación de Bizkaia, 2003).
} 
pasado, la cual quedó interrumpida por la Guerra Civil. ${ }^{3}$ No fue sino a partir de los años cincuenta y hasta la década de los setenta, fuera de los límites de este trabajo en todo caso, cuando la comarca asistiría a su definitiva industrialización de la mano de los municipios de Laudio/Llodio, Amurrio y, en mucha menor medida, de Urduña/Orduña. Estos fueron siempre los municipios más dinámicos e impulsores del desarrollo económico de la comarca, por lo que centraremos nuestro análisis en ellos.

El objetivo del presente trabajo consiste en analizar el proceso de alfabetización en la comarca, atendiendo a su cronología y principales características, en lo que es tanto un estudio de caso concreto que contribuirá al mayor conocimiento de las distintas casuísticas alfabetizadoras en el País Vasco como una reflexión en torno a la educación formal como medio de mejora del capital humano y sobre la relación de éste con el desarrollo económico.

Para ello, haremos uso básicamente de datos extraídos de padrones de población correspondientes a los citados tres municipios en dos periodos distintos: a finales del siglo XIX, entre 1890 y 1900 en función de la localidad, y en 1935. Los padrones reflejan la posesión de las capacidades de leer y escribir para todos los individuos que aparecen en ellos, de modo que constituyen una foto fija de la situación alfabetizadora de una localidad en un momento determinado. Habitualmente, los padrones son el recurso más habitual y valioso para analizar la situación en materia de alfabetización de una población concreta en un momento dado, especialmente porque proporciona la posibilidad de combinar esa información con otra serie de variables que aparecen en los padrones como la edad, género, procedencia o profesión de cada individuo.

\section{ALFABETIZACIÓN, CAPITAL HUMANO Y DESARROLLO ECONÓMICO}

Habitualmente, los estudios sobre el proceso de alfabetización han tenido como objetivo no solo el análisis per se de este fenómeno histórico concreto, sino que se han puesto en relación con la puesta en marcha

\footnotetext{
3 Aketza Merino Zulueta, «El Alto Nervión: La cara oculta de la modernización vasca (1876-1936): otras funciones, otros ritmos» (Trabajo de Fin de Máster, Universidad del País Vasco, 2011).
} 
- $\mathrm{O}$ no- de procesos de desarrollo económico. En ocasiones, los investigadores olvidamos que el factor humano es fundamental en todo proceso de desarrollo: al fin y al cabo, son las personas de carne y hueso las que hacen posible que las inversiones financieras y las innovaciones tecnológicas tengan éxito. En este sentido, se habla del capital humano como la «capacidad productiva de un individuo o de un conjunto de individuos», y como tal valor sería mejorable mediante la adquisición de conocimientos teóricos y prácticos, de modo que la educación ha sido definida como una «adición que se hace a esa capacidad productiva por medio del aprendizaje». ${ }^{4}$ Por lo tanto, la educación sería al capital humano el equivalente de la inversión al capital físico: los avances efectivos en educación permitirían llevar a cabo una mayor y mejor explotación de los recursos, ya que aquella incentiva la innovación en las técnicas de producción y la adaptación a las condiciones locales de tecnologías desarrolladas en otros países. ${ }^{5}$ Es desde esta perspectiva que el análisis del capital humano ha cobrado pleno sentido como parte de los estudios sobre modernización y desarrollo.

La idea subyacente a dicho concepto ya fue puesta de manifiesto por economistas clásicos como J. Stuart Mill, quien incidió en el escaso reconocimiento que se concedía al valor económico de la difusión del conocimiento. La formulación explícita del concepto se produjo de la mano de los primeros autores que trataron de medir numéricamente los efectos de este factor, como R. Solow ${ }^{6}$ y posteriormente T. W. Schultz. ${ }^{7}$ Fue este último quien concluyó que había un factor de producción, aún no mensurado, al que llamó capital humano: «humano porque está incorporado al hombre, y [...] capital porque es fuente de satisfacciones futuras, de ganancias futuras, o de ambas cosas».8 Schultz consideró que estos «atributos cualitativos» de la población podían ser mejorados

\footnotetext{
${ }^{4}$ Clara Eugenia Núñez y Gabriel Tortella (eds.), La maldición divina. Ignorancia y atraso histórico en perspectiva histórica (Madrid: Alianza, 1993), 20.

5 Sidney Pollard, Peaceful Conquest: The Industrialization of Europe 1760-1970 (Oxford: Oxford University Press, 1982).

' Robert Solow, «Technical Change and the Aggregate Production Function», Review of Economics and Statistics 39 (1957): 312-320.

7 Theodore William Schultz, «The value on the ability to deal with disequilibria», Journal of Economic History 39, no. 3 (1975): 827-846.

8 Núñez y Tortella, La maldición divina, 20.
} 
e incrementados mediante una inversión apropiada, papel que recaería especialmente en la educación formal.

En efecto, la educación formal, entendida como sinónimo de escolarización y alfabetización de los individuos, se ha considerado como el factor fundamental, y más fácilmente medible, de la inversión en capital humano. Es cierto, y no hay que dejar de incidir en ello, que la educación tiene una cara informal, de aprendizaje, que no está vinculada a la escuela, la universidad u otros centros de formación reglada. La educación no es la única forma de 'inversión' en capital humano ni mucho menos. Sin embargo, los estudios que tratan sobre la formación del capital humano se suelen centrar en ella porque constituye la forma de aprendizaje más próxima y fácil de mensurar frente a otros elementos que también forman parte del aprendizaje del individuo pero que son difíciles de documentar, medir y valorar. No todos los aspectos pueden ser reducidos a una cifra ni asimilados según parámetros económicos.

Sin embargo, esta postura, ampliamente compartida por economistas y científicos sociales, fue objeto de las críticas de una corriente escéptica que cuestiona el valor de la educación como adición al capital humano si no incluye las capacidades específicas que se requieren para un puesto de trabajo concreto. ${ }^{9}$ Es decir, los escépticos creen que «la única educación con valor económico es la enseñanza de un oficio o una técnica, comenzando con la lectura, la escritura y las cuentas». ${ }^{10}$ En este sentido, D. Mitch afirma que en sectores como la industria o la agricultura no sería necesaria la alfabetización de la mayoría de la fuerza de trabajo para que se produzca un progreso científico-técnico.

De todos modos, la relación positiva entre desarrollo y educación es generalmente admitida, aunque no se haya logrado un consenso acerca de la naturaleza de dicha relación debido a las dificultades de los investigadores para fusionar la teoría del capital humano con los trabajos empíricos. ¿Hasta qué punto la educación contribuye a mejorar la

\footnotetext{
9 David Mitch, «Educación y crecimiento económico: ¿Otro axioma de indispensabilidad? Del capital humano a las capacidades humanas», en La maldición divina. Ignorancia y atraso económico en perspectiva histórica, eds. Clara Eugenia Núñez y Gabriel Tortella (Madrid: Alianza Universal, 1993), 41-60.

${ }^{10}$ Núñez y Tortella, La maldición divina, 29.
} 
capacidad de los individuos para utilizar los conocimientos adquiridos con el objetivo de innovar, crear, adaptar y, en definitiva, prosperar y mejorar su situación individual y la de la sociedad? Uno de los autores que ha estudiado los efectos de la educación formal en las capacidades de los individuos, desde un punto de vista psicológico, fue A. R. Luria, quien concluyó que la alfabetización producía importantes cambios en la actividad mental humana. El proceso de aprendizaje crearía nuevos motivos de acción afectando a la estructura del proceso cognitivo. ${ }^{11}$ En todo caso, los estudios empíricos, y el nuestro no es una excepción, se han centrado más en analizar la relación entre la alfabetización y la revolución industrial como fenómeno histórico concreto que en abordar la relación entre aquella y el desarrollo económico en general.

No cabe duda de los efectos positivos de la educación sobre la población y el conjunto de la sociedad, eliminando el analfabetismo, pero no es menos cierto que su contribución exacta a los procesos de desarrollo económico es realmente complicada de medir. ${ }^{12}$ Schultz consideró que la aportación más importante de la educación al crecimiento económico consiste en la capacidad de adaptación al cambio. ${ }^{13}$ En este sentido, autores como R. Easterlin, R. Cameron o W. Baumol consideran que el nivel educativo de la población determina la rapidez y facilidad con que se adopta, y se adapta a las condiciones locales, la tecnología importada. ${ }^{14}$ L. G. Sandberg constató que la acumulación de capital humano mejoraba los resultados económicos a medio plazo $^{15} \mathrm{y}$ autores como C. E. Núñez o F. Collantes, en el caso español, concluyeron que una deficiente dotación de capital humano debido a la lenta y tardía alfabetización obstaculizó la modernización económica y social, mientras que aquellas regiones más avanzadas en lo educativo se situaron en los

\footnotetext{
11 Aleksandr Románovich Luria, Cognitive Development. Its Cultural and Social Foundations (Cambridge: Cambridge University Press, 1976), 161.

12 Núñez y Tortella, La maldición divina, 223.

13 Theodore William Schultz, Investing in People. The Economics of Population Quality (Berkeley: University of California Press, 1981).

14 Núñez y Tortella, La maldición divina, 223.

15 Lars G. Sandberg, «Ignorance, poverty and economic backwardness in the early stages of European industrialization: variations on Alexander Gerschenkron's grand theme», Journal of European Economic History 11, no. 3 (1982): 675-697.
} 
primeros lugares en cuanto a desarrollo económico. ${ }^{16}$ De todos modos, demostrar empíricamente la existencia de esta correlación entre educación y desarrollo no es tarea fácil para las ciencias sociales.

En este contexto, en 1963 M. J. Bowman y C. A. Anderson realizaron una aportación de gran importancia, ya que, de alguna manera, su teoría de los umbrales de alfabetización permite establecer comparaciones a lo largo del tiempo y valorar en qué punto se encuentra una determinada sociedad dentro de la transición desde una alfabetización restringida a una universal. ${ }^{17}$ Esta teoría presupone la existencia de dos umbrales que marcan el paso a la siguiente fase en un proceso de desarrollo, umbrales que se definen en función del porcentaje de población alfabetizada que existe en una sociedad concreta. El primer umbral estaría situado en unos porcentajes entre el 30 y el $40 \%$ de población mayor de diez años alfabetizada; unas tasas inferiores a esas cifras constituirían un obstáculo importante al crecimiento económico. El segundo umbral se situaría en torno al 70\% de población adulta alfabetizada; una vez alcanzadas y superadas estas tasas, sería posible el éxito en la puesta en marcha de un proceso de desarrollo.

Aunque no es una herramienta exenta de objeciones, en el presente trabajo manejaremos estos umbrales como referencia para calibrar los logros del proceso alfabetizador en la comarca del Alto Nervión y como elemento comparativo con las cifras obtenidas por otros autores que también los han empleado en la historiografía española y vasca. De esta manera, podremos obtener una visión de conjunto más completa acerca de la alfabetización en el País Vasco y los territorios que lo integran.

Dicho lo cual, precisamos que asumimos la definición de la alfabetización como

una habilidad positiva que proporciona ventajas a los individuos, como mayores posibilidades de acceso al mercado laboral, a la información, a las redes sociales, etc. A la población alfabeta se le

\footnotetext{
${ }_{16}$ Clara Eugenia Núñez, La fuente de la riqueza. Educación y desarrollo económico en la España contemporánea (Madrid: Alianza Universidad, 1992); Fernando Collantes Gutiérrez, "¿Fue el capital humano importante para la diversificación económica de la España rural (1950-1991)?», Revista de Demografía Histórica 25, no. 1 (2007): 168-169.

${ }_{17}$ Mary Jane Bowman y C. Arnold Anderson, "Concerning the Role of Education in Development», en Old Societies and New States, ed. Clifford Geertz (Glencoe: The Free Press, 1963), 247-269.
} 
presuponen mayores oportunidades para el futuro, la oportunidad de alcanzar más fácilmente el éxito y una mejor inserción en el mercado laboral (en puestos de trabajo y con sueldo superiores), en definitiva, mayores posibilidades de ascenso social. Asimismo, la alfabetización puede influir en una mayor apertura de las personas frente a ideas nuevas y una mayor capacidad de adaptación a un mundo en rápida evolución..$^{18}$

El proceso de alfabetización, entonces, trataría de la transición de una situación de alfabetización restringida a otra de alfabetización universal. Este es un proceso reciente, que ha tenido lugar como máximo en el intervalo de los dos últimos siglos. El concepto de alfabetización restringida fue acuñado por J. Goody al estudiar aquellos obstáculos materiales, limitaciones tecnológicas y restricciones sociales que limitaban el acceso a la alfabetización. ${ }^{19}$ En este sentido, en estos procesos es de gran importancia el papel de la familia, ya que la educación formaba parte (o no) de las estrategias adoptadas para la supervivencia de la familia y de los miembros que la integran..$^{20}$ A la hora de adoptar esta decisión, son varios los factores que subyacen a ella, como el nivel de alfabetización de los progenitores y el estatus socioeconómico de la familia.

Con la modernización, la adopción por parte del Estado de la atribución de formar a la población, y con la imposición de la obligatoriedad de la escolarización a partir de determinada edad, la capacidad decisora de la familia se restringe, si bien siguió manteniendo su poder, así como sus resquicios de resistencia, como por ejemplo, el absentismo escolar, a favor de cubrir otra serie de necesidades internas de la familia, como las productivas. ${ }^{21}$

En definitiva, los estudios empíricos nos han mostrado que unas elevadas tasas de alfabetización sean indispensables para que un proceso

\footnotetext{
${ }_{18}$ Rocío García Abad, Arantza Pareja Alonso y Karmele Zarraga Sangroniz, «¿Sabe leer? ¿Sabe escribir? El proceso de alfabetización en el País Vasco», Revista de Demografía Histórica 25, no. 1 (2007): 25.

19 Jack Goody, Literacy in Traditional Societies (Cambridge, Cambridge University Press, 1968).

${ }^{20}$ García, Pareja y Zarraga, «¿Sabe leer? ¿Sabe escribir?», 46.

${ }^{21}$ García, Pareja y Zarraga, «¿Sabe leer? ¿Sabe escribir?», 47.
} 
de desarrollo económico tenga éxito. Una sociedad alfabetizada se encuentra mucho mejor preparada para modernizarse, pues es más proclive a la innovación, a la adaptación de tecnologías y técnicas importadas. Pero ¿es la consecución de una población convenientemente preparada en materia educativa un factor que por sí solo sea capaz de activar e impulsar un proceso de desarrollo?

\section{EL PUNTO DE PARTIDA: EL SISTEMA ESCOLAR TRADICIONAL}

Los primeros datos sobre alfabetización de los que disponemos datan de mediados del siglo XIX. Por entonces, las provincias vascas se encontraban entre aquellas con mayores niveles de alfabetización de todo el Estado. Pero la situación era desigual en función de la provincia, ya que las diferencias entre ellas eran notables. Curiosamente, era la rural provincia de Araba/Álava la que tenía las mayores tasas de alfabetización del Estado. No en vano, en 1860 los hombres alaveses estaban en puertas de alcanzar el segundo umbral de alfabetización definido por Bowman y Anderson. El fomento de la educación fue una cuestión central para las élites vascas decimonónicas en general y las alavesas en particular. Así lo manifestaba Vicente Vera a comienzos del siglo XX: "Álava ha figurado siempre a la cabeza de las provincias que han mostrado interés en desarrollar la enseñanza pública».22 Claro que ello se vio favorecido por otros factores como la habitual distribución de la población en localidades de pequeño tamaño y hábitat concentrado.

Desde mediados del siglo XIX, la cuestión de la instrucción pública fue objeto de interés para la mayor parte de los diputados generales de Araba/Álava. Un ejemplo de ello es la figura de Ramón Ortiz de Zárate, diputado general y diputado en Cortes, quien insistentemente resaltaba el gran logro que suponían los altos niveles de alfabetización conseguidos por Araba/Álava. ${ }^{23}$ Por su parte, otro notable alavés, Ricardo Becerro de Bengoa, defendía la instrucción pública como el pilar fundamental

\footnotetext{
22 Francesc Carreras Candi, Geografía general del País Vasco (Bilbao: La Gran Enciclopedia Vasca, 1980), 118.

${ }_{23}$ Xabier Ormaetxea Garai, «Ramón Ortiz de Zárate Martínez de Galarreta (1817-1883). Biografía político-institucional y análisis político de su figura u obra entre 1840 y 1858» (Trabajo de Fin de Máster, Universidad del País Vasco, 2011).
} 
para la reforma social, elemento clave para regenerar la sociedad y solucionar sus problemas. ${ }^{24}$

De todos modos, y a pesar de los impulsos recibidos desde arriba, no hay que olvidar que la consecución de unos altos niveles de alfabetización no hubiera sido posible si la población alavesa no hubiese sido partícipe de ese interés. Así, parte de este gran logro corresponde también a los concejos alaveses, que eran quienes buscaban y contrataban a los maestros, y a los padres de familia, que al fin y al cabo eran quienes decidían en el seno de los concejos, y quienes hacían posible la eficacia de la labor educativa al permitir que sus hijos acudiesen a la escuela en vez de retenerlos en las explotaciones familiares por la necesidad de mano de obra.

Por lo tanto, Araba/Álava fue siempre una provincia muy bien escolarizada. En la era preindustrial, la escolarización primaria se basaba en la adquisición de las capacidades de leer y escribir, así como en el adoctrinamiento religioso, casi siempre en escuelas incompletas dependientes de ayuntamientos o concejos con poco presupuesto. En ámbitos vascoparlantes, además, la escuela era el lugar donde los jóvenes aprendían castellano. La escuela también tenía un componente de control por parte de las autoridades, ya que la enseñanza se consideraba fundamental:

para formar buenos ciudadanos, para hacerlos dóciles y obedientes de costumbres morigeradas, arraiga en ellos los hábitos de laboriosidad y de trabajo y les dispensa en fin con la tranquilidad de sus conciencias, toda la posible prosperidad y bienestar. ${ }^{25}$

No parece que los diversos cambios legislativos y políticos tuvieran demasiada influencia en el funcionamiento de las escuelas alavesas, donde eran las Juntas Generales quienes tenían competencia sobre la Instrucción Primaria, Secundaria y de Ampliación. Sin embargo, en el siglo XIX, las tensiones afloraron entre unas instituciones provinciales cada vez más poderosas y con atribuciones en materia educativa, unos municipios encargados de seleccionar y pagar a los maestros, y los

\footnotetext{
${ }^{24}$ Gonzalo Capellán de Miguel, Ricardo Becerro de Bengoa. La enseñanza en el siglo XX (Leioa: Servicio Editorial de la UPV/EHU, 2001).

25 Ladrón de Guevara, La conformación del sistema, 90.
} 
gobiernos liberales deseosos de crear un sistema nacional de instrucción pública como parte de su proyecto nacionalizador. ${ }^{26}$

La Ley Moyano en 1857 preconizaba la centralización y uniformización de la enseñanza, y establecía el carácter obligatorio y gratuito de la misma al menos entre los seis y los nueve años. Por su parte, las tres Diputaciones vascas trataron de evitar la aplicación de la Ley por considerar que su buena situación en materia educativa era fruto precisamente de la autonomía foral de la que venían gozando en la materia. Otros puntos de fricción con el gobierno central fueron el rechazo al control de la enseñanza por parte de las Juntas de Instrucción o el deseo de las Diputaciones de que los maestros fueran naturales de la tierra y conocedores del euskera. En resumen, las diputaciones se oponían a la Ley Moyano porque dejaba el control de la enseñanza en manos del Estado y finiquitaba el modelo educativo desarrollado por las instituciones forales hasta el momento, un modelo que se podría calificar de exitoso a la vista de los resultados. ${ }^{27}$

En Araba/Álava, la Diputación edificaba las escuelas y los ayuntamientos se encargaban de mantener el edificio y al maestro. ${ }^{28}$ Según P. Madoz, en 1824 había en la provincia un maestro por cada 285 habitantes y 21 niños por maestro. ${ }^{29}$ Una cifra excelente desde el punto de vista comparativo en relación con otras provincias. No en vano, las autoridades forales habían obligado a establecer escuelas a aquellos pueblos que contaran con más de 100 habitantes, aunque fueran en su mayoría incompletas y la enseñanza no fuera obligatoria. De este modo, casi todos los pueblos alaveses contaban con escuela. Sin embargo, la Ley Moyano establecía la obligatoriedad de una escuela por cada 500 habitantes, lo cual habría supuesto una concentración escolar que habría provocado la desaparición de numerosas escuelas.

\footnotetext{
${ }^{26}$ Ernesto Ladrón de Guevara López de Arbina, La conformación del sistema educativo en Álava (1860-1936): centralización y foralismo (Vitoria-Gasteiz: Diputación Foral de Álava-Departamento de Cultura, 2000), 41.

27 José Daniel Reboredo Olivenza, «La organización administrativa de la primera enseñanza decimonónica (1825-1930)», Sancho el Sabio 5 (1995): 308.

${ }^{28}$ Ladrón de Guevara, La conformación del sistema, 49.

29 Pascual Madoz, Diccionario geográfico-estadístico-histórico. Álava (Valladolid: Ámbito, 1989), 24.
} 
Según la ley, existían en 1860 en el País Vasco, entre escuelas públicas y privadas: 60 en Álava, 89 en Gipuzkoa y 70 en Bizkaia. La relación entre escuela/alumno era de las más altas de España en esta fecha, arrojando una relación por habitante de 1/263 en Álava, 1/497 en Gipuzkoa y 1/504 en Bizkaia. La media española era de $1 / 561 .{ }^{30}$

Finalmente, las provincias vascas consiguieron que la instrucción pública de las provincias quedara en poder de las diputaciones. Los poderes forales consideraban la instrucción primaria como la base de la prosperidad y, por lo tanto, eran conscientes de la necesidad de su potenciación y financiación, a pesar de lo cual los ayuntamientos reducían costes en cuanto podían, fundamentalmente el sueldo del maestro.

El Alto Nervión no fue ajeno a la gran importancia concedida a la educación por las élites, autoridades y padres de familia. En el diccionario de Madoz, de mediados del XIX, el apartado correspondiente al Partido Judicial de Amurrio, que abarcaba comarcas ajenas al Alto Nervión como Valdegovía, afirmaba que existían 29 escuelas en los 68 pueblos que lo integraban, de las cuales 6 eran de ambos sexos y 23 elementales incompletas. Las primeras reunían 345 niños y 160 niñas, y las segundas 404 niños y 156 niñas, por lo que la diferencia por sexos era bastante notable. ${ }^{31}$ Como veremos, la convergencia de las cifras de ambos sexos será uno de los grandes retos del proceso alfabetizador.

En todo caso, es posible que estas informaciones no sean del todo fiables, ya que si en este mismo diccionario se consulta la información particular de cada pueblo del Alto Nervión, se observa que tan solo en esta comarca ya había 26 escuelas. Por supuesto, las principales localidades de la comarca contaban con sus correspondientes escuelas. En Amurrio existía una elemental completa a la que asistían 51 niños y 27 niñas. ${ }^{32}$ En Laudio/Llodio, con mayor población, acudían 100 niños y 43 niñas. ${ }^{33}$ Urduña/Orduña presenta los perfiles más avanzados en este

\footnotetext{
30 Paulí Dávila Balsera, La política educativa y la enseñanza pública en el País Vasco (1860-1930) (San Sebastián: Ibaeta Pedagogía, 1995), 53.

31 Madoz, Diccionario geográfico-estadístico, 78.

32 Madoz, Diccionario geográfico-estadístico, 76.

33 Madoz, Diccionario geográfico-estadístico, 150.
} 
sentido; no obstante, existía una escuela para niños a la que asistían 140 alumnos, y otra escuela para niñas concurrida por 56 alumnas, además de una privada a la que acudían 18 niñas. ${ }^{34}$

En el resto del territorio, existían escuelas en casi todas las localidades excepto en las más pequeñas. La más concurrida parece ser la de Baranbio - localidad que aún era plenamente euskaldun-, que contaría entonces incluso con mayor número de alumnos que la de Amurrio, 67 niños y 26 niñas. ${ }^{35}$ En el área occidental, la villa de Artziniega contaba con una escuela a la que asistían unos 50 niños. ${ }^{36}$ En Arrastaria, las escuelas se establecieron en Delika y Tertanga, acudiendo a éstas los habitantes de los otros dos pueblos. ${ }^{37}$ Por su parte, la escuela del valle de Okondo estaba bastante concurrida con la asistencia de unos 70 alumnos. ${ }^{38}$ Finalmente, en el municipio de Ayala/Aiara las escuelas se concentraban en las localidades de mayor población como Luiaondo, Arespalditza/Respaldiza, Zuaza/Zuhatza, Soxo/Soxo, Menagarai o Llanteno, aunque también las había en Añes, Retes de Llanteno, Costera/Opellora, Izoria y Menoio.

En definitiva, a mediados del siglo XIX la oferta educativa en el Alto Nervión ya era, cuanto menos, aceptable. La mayoría de localidades contaba con, al menos, una escuela, aunque la mayoría fueran incompletas, típicas del mundo rural, en las que no existía separación de alumnos ni por edad ni por sexo. Habrá que esperar al siglo XX para que algunas de estas localidades rurales construyan escuelas específicas para niñas, dando el impulso definitivo hacia la alfabetización universal. Aun así, los datos nos sugieren que, en la segunda mitad del XIX, la oferta educativa en el Alto Nervión, por muy básica que fuera, alcanzaba a todos sus rincones, excepto a aquellas localidades de menor tamaño, incapaces de sostener una escuela por sí mismas. Veremos a continuación cuáles fueron los logros reales de esta red de centros educativos.

\footnotetext{
34 Madoz, Diccionario geográfico-estadístico, 166.

35 Madoz, Diccionario geográfico-estadístico, 102.

36 Madoz, Diccionario geográfico-estadístico, 90.

37 Madoz, Diccionario geográfico-estadístico, 117 y 185.

38 Madoz, Diccionario geográfico-estadístico, 165.
} 


\section{EL PROCESO DE ALFABETIZACIÓN EN EL ALTO NERVIÓN A FINALES DEL SIGLO XIX}

En 1887 el 65\% de la población total alavesa ya estaba alfabetizada y los hombres habían superado el segundo umbral de alfabetización. Por estos años, las diputaciones obtuvieron el beneplácito del gobierno para seguir gestionando el pago de los salarios del profesorado y la enseñanza en general, que continuaba dependiendo de las juntas locales de Instrucción Pública, esto es, ayuntamientos y concejos. ${ }^{39}$ Sin embargo, la provincia afrontaba una gran crisis económica, incapaz de modernizar su economía y de competir con las provincias costeras, en plena expansión industrial, lo que provocó una intensa emigración en todo el territorio.

Hacia 1884 existían 31 escuelas en la Cuadrilla de Ayala —excluyendo el vizcaíno ayuntamiento de Urduña/Orduña-, en las que había un total de 1.112 matriculados, sorprendentemente con mayor número de niñas que de niños. ${ }^{40}$ Unos años después, S. Mendia apuntaba que solo en el municipio de Ayala/Aiara existían 20 escuelas de primera enseñanza: tres elementales de niñas y 17 de ambos sexos. ${ }^{41}$ De ser cierta esta información, supondría que casi todas las localidades del municipio contarían con su propia escuela, ya que eran 23 pueblos en total, lo que sería una muestra del gran avance experimentado por la instrucción pública durante la segunda mitad del siglo XIX. Sin embargo, datos próximos al año 1910 apuntan a una menor cantidad de escuelas en el municipio. Seguramente, el gran descenso demográfico ocurrido a finales del siglo XIX en esta comarca —entre 1860 y 1910 municipios como Ayala/ Aiara y Lezama perdieron el $32,45 \%$ y el $29,27 \%$ de sus respectivas poblaciones- provocó la desaparición de algunas de las escuelas menos concurridas. ${ }^{42}$

Para estudiar la situación del proceso alfabetizador en esta década final del siglo XIX, nos serviremos de los datos proporcionados por los padrones de población de los municipios de Amurrio, Laudio/Llodio y

\footnotetext{
39 Ladrón de Guevara, La conformación del sistema, 115.

${ }^{40}$ Ladrón de Guevara, La conformación del sistema, 115.

${ }_{41}$ Santiago Mendia, El condado de Ayala (Vitoria-Gasteiz: Diputación Foral de Álava, 1994), 28.

${ }^{42}$ Ladrón de Guevara, La conformación del sistema, 117.
} 
Urduña/Orduña, correspondientes a los años 1891, 1890 y 1900, respectivamente. En todo caso, antes de iniciar el análisis de los datos, debemos precisar que el padrón de Laudio/Llodio no diferencia entre las capacidades de leer y escribir, sino que las incluye en una misma categoría. Por ello, no aparecen semialfabetos, los cuales sí están presentes en los otros dos municipios. De todos modos, aquellos que sabían leer y escribir aventajaban a los que solo sabían leer en Amurrio y Urduña/Orduña en cuatro y dos puntos porcentuales, respectivamente. Dicho esto, y considerando que la diferencia no era demasiado acusada, tomaremos como referencia las cifras máximas, es decir, las que contabilizan a alfabetos y semialfabetos.

La tasa total de alfabetización de la población mayor de diez años en el conjunto de las tres localidades era del $61,13 \%$ en estos momentos finales del siglo XIX. Ello significa que el primer umbral de alfabetización ya había sido superado ampliamente pero todavía se estaba lejos de alcanzar el segundo. También se encontraba notablemente por debajo del $74 \%$ de alfabetización que presentaba la provincia de Araba/Álava en el año 1900. No alcanzaba, incluso, el 63\% de Bizkaia pero, en todo caso, superaba de manera holgada la media española, situada en un escaso $41 \% .{ }^{43}$ A pesar de que el Alto Nervión estaba en estos años conteniendo a duras penas los efectos de una regresión plasmada en un importante descenso demográfico, también superaba, aunque por estrecho margen, las tasas de una zona parcialmente inmersa en un proceso de desarrollo como el guipuzcoano valle del Deba. ${ }^{44}$

En todo caso, hay que tener en cuenta que si tomásemos el conjunto del Alto Nervión, incorporando también los municipios de mayor carácter rural, sin duda las tasas de alfabetización resultantes serían menores que las de la muestra que estamos tratando. No cabe duda que estos municipios rurales tendrían unas tasas inferiores no solo a Urduña/Orduña, que mostraba un perfil muy avanzado en este sentido, sino también a Laudio/Llodio y Amurrio que, si bien continuaban siendo localidades esencialmente agrarias, presentaban ya algunos caracteres más

\footnotetext{
${ }_{43}$ Maitane Ostolaza Esnal, Entre religión y modernidad: los colegios de las congregaciones religiosas en la construcción de la sociedad guipuzcoana contemporánea: 1876-1931 (Bilbao: UPV-EHU, 2000), 51.

44 Manuel González Portilla, José Urrutikoetxea Lizarraga y Karmele Zarraga Sangroniz, La «otra industrialización» del País Vasco: las pequeñas y medianas ciudades: capital humano e innovación social durante la primera industrialización (Bilbao: Editorial UPV/EHU, 2015), 236.
} 
dinámicos que los diferenciaban de los pueblos acentuadamente rurales, sobre todo Amurrio.

La situación en materia alfabetizadora en la zona más rural la podemos valorar analizando áreas como los barrios de montaña de Amurrio, plenamente rurales y alejados del núcleo de la localidad, los cuales presentaban una tasa del 50\% de alfabetización en los mayores de diez años, cifra más de 20 puntos inferior al índice de alfabetización de los barrios del centro.

Cuadro 1. Alfabetización por municipios y género, mayores de 10 años (1890/1900)

\begin{tabular}{|l|l|c|c|}
\hline \multirow{4}{*}{ Amurrio } & & $\mathbf{n}^{\mathbf{0}}$ & \% \\
\hline \multirow{5}{*}{ Laudio/Llodio } & Hombres & 264 & 68,93 \\
\cline { 2 - 4 } & Mujeres & 230 & 53,36 \\
\cline { 2 - 4 } & TOTAL & $\mathbf{4 9 4}$ & $\mathbf{6 0 , 6 9}$ \\
\hline \multirow{4}{*}{ Urduña/Orduña } & Hombres & 466 & 60,28 \\
\cline { 2 - 4 } & Mujeres & 281 & 34,86 \\
\cline { 2 - 4 } & TOTAL & $\mathbf{7 4 7}$ & $\mathbf{4 7 , 3 1}$ \\
\hline \multirow{5}{*}{ Alto Nervión } & Hombres & 682 & 83,27 \\
\cline { 2 - 4 } & Mujeres & 612 & 65,45 \\
\cline { 2 - 4 } & TOTAL & $\mathbf{1 2 9 4}$ & $\mathbf{7 3 , 7 7}$ \\
\hline & Hombres & 1423 & 72,05 \\
\cline { 2 - 4 } & Mujeres & 1112 & 51,2 \\
\cline { 2 - 4 } & TOTAL & $\mathbf{2 5 3 5}$ & $\mathbf{6 1 , 1 3}$ \\
\hline
\end{tabular}

Fuente: elaboración propia a partir de los padrones.

A continuación, analizaremos las tasas de alfabetización según tramos de edad con el objetivo de observar cuándo aquellas despegaron, y así aproximarnos al momento en que la alfabetización comenzó a generalizarse entre la población del lugar. Primero, en el Cuadro 2 se aprecia claramente que Urduña/Orduña se sitúa a la cabeza en todo momento, y en todas y cada una de las franjas de edad. Destacan especialmente los tramos comprendidos entre los 15 y los 25 años, con tasas por encima 
del $85 \%$ de alfabetizados, y aún hasta los 29 años se mantienen tasas superiores al $80 \%$. De este modo, parece que en la ciudad vizcaína la actividad alfabetizadora se intensificó a partir de 1870 aunque, en todo caso, las tasas eran bastante elevadas, al menos hasta las personas nacidas en 1840 . No es casualidad que precisamente en torno a 1870 se estableciera en la ciudad un colegio de jesuitas. ${ }^{45}$

Cuadro 2. Alfabetización por tramos de edad, mayores de 10 años (1890/1900) (\%)

\begin{tabular}{|l|c|c|c|}
\hline & Amurrio & Laudio/Llodio & Urduña/Orduña \\
\hline $10-14$ & 65,42 & 64,25 & 77,27 \\
\hline $15-19$ & 62,34 & 61,41 & 89,77 \\
\hline $20-24$ & 72,22 & 49,03 & 86,14 \\
\hline $25-29$ & 66,67 & 46,2 & 81,12 \\
\hline $30-34$ & 58,54 & 53,1 & 74,82 \\
\hline $35-39$ & 69,12 & 53,7 & 70,91 \\
\hline $40-44$ & 60,29 & 44,44 & 71,24 \\
\hline $45-49$ & 62,5 & 38,26 & 76,22 \\
\hline $50-54$ & 58,54 & 41,25 & 63,64 \\
\hline $55-59$ & 54,84 & 24,72 & 66,67 \\
\hline $60-64$ & 43,64 & 38,83 & 45,9 \\
\hline $65-69$ & 41,03 & 31,17 & 59,68 \\
\hline $70-74$ & 57,69 & 34,62 & 60,66 \\
\hline $75-79$ & 50 & 18,18 & 52,38 \\
\hline$>=80$ & 20 & 10,53 & 30 \\
\hline & & & \\
\hline
\end{tabular}

Fuente: elaboración propia a partir de los padrones.

Por su parte, en Amurrio la franja de edad que tenía un mayor porcentaje de alfabetizados era la comprendida entre los 20 y los 24 años,

\footnotetext{
45 Archivo Municipal de Urduña/Orduña: Libro de Actas entre el siete de junio de 1868 y el treinta de diciembre de 1877. 0369/001.
} 
seguida de la comprendida entre los 35 y los 39. De todos modos, las tasas de alfabetización en esta localidad fluctúan notablemente de una franja de edad a otra sin que exista una tendencia demasiado definida. Se puede decir que, si bien a mediados del siglo XIX Amurrio no se encontraba en una posición muy retrasada respecto a Urduña/Orduña, en el resto de la centuria no llegó a experimentar el salto cualitativo que sí protagonizó la ciudad vizcaína.

Finalmente, Laudio/Llodio se sitúa a la cola en todas y cada una de las franjas de edad. Sus tasas de alfabetización en mayores de 60 años, y especialmente entre los más ancianos, eran realmente reducidas. Sin embargo, es apreciable en los datos el avance experimentado desde 1880. A buen seguro esto se debió a la actividad benéfica realizada por Estanislao de Urquijo Landaluce, el primer Marqués de Urquijo, quien, en 1866, creó unas escuelas en las que recibían una enseñanza gratuita y voluntaria una media de 112 niños por año. De hecho, Becerro de Bengoa señalaba que su creación incrementó la asistencia a las mismas en un 29,51\%, lo que explica perfectamente el aumento de las tasas de alfabetización a partir de este momento. ${ }^{46}$ En 1879 Mañé y Flaquer afirmaba en El Oasis:

En Llodio, todos los niños asisten a las escuelas y todos son educados al amor del catolicismo y de la caridad cristiana, y no hay en Europa ni en el mundo un solo pueblo donde en proporción a sus habitantes sean tantos los que sepan leer y escribir. ${ }^{47}$

Evidentemente, como hemos visto, los datos disponibles no refrendan esta última afirmación, sino que muestran todo lo contrario.

Centrándonos en estos tres municipios, la tasa de alfabetización del conjunto de los mismos oculta importantes diferencias en cuanto a sus capacidades alfabetizadoras, diferencias que son sobre todo de índole territorial y de género, pero también en función de la actividad profesional y la procedencia. Atenderemos a ello a continuación.

\footnotetext{
${ }^{46}$ Ricardo Becerro de Bengoa, La enseñanza en el siglo XX (Madrid: Ed. Edmundo Capdeville, 2009).

${ }^{47}$ Ladrón de Guevara, La conformación del sistema, 87.
} 


\section{Diferencias entre localidades}

En primer lugar, se aprecia una gran disparidad entre los municipios de la comarca, lo cual pone de manifiesto que, incluso en ámbitos tan reducidos como el que nos ocupa, los matices son absolutamente necesarios. En primer lugar, Urduña/Orduña se encontraba en una excelente situación con unos índices del 73,77\% de alfabetizados, por lo que la ciudad vizcaína ya había alcanzado el segundo umbral, lo que ni mucho menos había bastado para emprender un proceso de desarrollo económico. De hecho, era una de las poblaciones más alfabetizadas de Bizkaia y prácticamente igualaba a ciudades como Donostia-San Sebastián. ${ }^{48}$ Por el contrario, las tasas de alfabetización de Laudio/Llodio se encontraban casi 24 puntos por debajo, ni siquiera alcanzaban el 50\%. Amurrio se situaba a medio camino entre ambos casos, con una tasa del $60,69 \%$, que lo aproximaba al comportamiento medio del conjunto de la comarca, un comportamiento, eso sí, muy influido por el mayor peso demográfico de Urduña/Orduña.

La gran diferencia existente entre Urduña/Orduña y Laudio/Llodio tenía un paralelismo en el caso del valle del Deba, ya que las tasas de alfabetización de Eibar y Oñati diferían por aquel entonces también en unos 20 puntos porcentuales. ${ }^{49}$ Sin embargo, las similitudes entre Eibar y Urduña/Orduña en este momento eran más bien escasas, por lo que consideramos que las tasas de alfabetización en esta comarca obedecían a unas lógicas distintas que aquellas que operaban en el Deba guipuzcoano.

\section{Diferencias por género}

La segunda característica de la alfabetización en el Alto Nervión en esta década final del siglo XIX era, como decíamos, la notable diferencia en función del género de 20 puntos porcentuales, puesto que las tasas de hombres y mujeres eran el $72,05 \%$ y del $51,2 \%$, respectivamente. No existían grandes diferencias entre los municipios en este aspecto. Urduña/

\footnotetext{
48 Manuel González Portilla y José Urrutikoetxea Lizarraga, «El capital humano en la primera modernización industrial vasca (1876-1930). Viejas herencias e innovaciones recientes», Revista de Demografía Histórica 34, no. 2 (2016): 73.

49 González, Urrutikoetxea y Zarraga, La «otra industrialización» del País Vasco, 236.
} 
Orduña presentaba la menor diferencia entre los dos sexos, de 20 puntos, la misma que en el conjunto de la comarca y en Amurrio. Por el contrario, Laudio/Llodio no solamente poseía la menor tasa de alfabetización total, sino que también hacía gala de la mayor diferencia en función del género: mientras que los hombres alcanzaban un respetable $60,28 \%$ de alfabetización, las mujeres solamente llegaban al 34,86\%.

En el año 1900, la diferencia en función del género de las tasas de alfabetización rondaba también los 20 puntos porcentuales tanto en la Bizkaia rural y urbana como en la Araba/Álava urbana, donde era incluso mayor. No era así en Gipuzkoa, ya que la diferencia era solamente de unos nueve puntos. ${ }^{50}$ Por lo tanto, independientemente de la diversidad de tasas entre los tres municipios, podemos decir que nuestra comarca era partícipe de un modelo común con Araba/Álava y Bizkaia en lo que respecta a la diferencia de alfabetización entre hombres y mujeres. Un modelo que no se daba en Gipuzkoa.

Los datos de 1860 muestran que la mayor diferencia por género se daba precisamente en Araba/Álava. Ello se debía a unas tasas de alfabetización masculina excepcionalmente altas. Este era el factor decisivo: eran tasas, en definitiva, de lo que se llama un modelo precoercitivo, característico de aquellas sociedades en las que la universalización de la alfabetización, que fue mucho más intensa entre los varones, precedió a la introducción de medidas coercitivas desde el gobierno para la instrucción pública. ${ }^{51}$ Nada sorprendente después de haber explicado la trayectoria educativa de la provincia de Araba/Álava, en la que se incluye la mayor parte del Alto Nervión. Por el contrario, el modelo postcoercitivo aparecería allí donde el primer umbral aún no habría sido superado en el momento en que se introdujeron medidas coercitivas y, por ello, al partir ambos de tasas muy bajas, el diferencial sexual en el proceso de transición suele ser menor.

\section{Diferencias según actividad profesional}

A las grandes diferencias existentes entre localidades y, en el seno de estas, en función del género, debemos sumar las diferentes capacidades

\footnotetext{
${ }^{50}$ García, Pareja y Zarraga, «¿Sabe leer? ¿Sabe escribir?», 33.

${ }_{51}$ Núñez, La fuente de la riqueza, 129.
} 
alfabetizadoras según la actividad profesional. En este sentido, estudiantes, profesionales liberales y élites eran los mejor preparados, ya que todos estaban alfabetizados. Prácticamente lo mismo podemos decir del sector servicios. Otro grupo profesional con altas tasas era el artesanado: en Urduña/Orduña y Laudio/Llodio presentaban unas tasas de alfabetización en torno al 95\%, aunque en Amurrio se quedaban en un $80 \%$. Resulta llamativo el dato referente a Laudio/Llodio, ya que en el valle alavés las tasas generales eran bastante bajas, por lo que, en comparación, la cualificación del artesanado era muy destacable.

Cuadro 3. Alfabetización de los hombres mayores de 10 años según actividad profesional (1890/1900) $(\%)$

\begin{tabular}{|l|c|c|c|}
\hline & Amurrio & Laudio/Llodio & Urduña/Orduña \\
\hline Artesanos & 80 & 95,2 & 94,06 \\
\hline Escolares & 100 & 67,3 & 84,85 \\
\hline Estudiantes & 100 & 100 & 100 \\
\hline Jornaleros & 78,05 & 63 & 74,68 \\
\hline Jubilados & 100 & 100 & 0 \\
\hline Labradores & 62,16 & 52 & 74,5 \\
\hline Liberales & 100 & 100 & 100 \\
\hline Pobres & 0 & 0 & 50 \\
\hline Servicios & 100 & 100 & 92,59 \\
\hline Sirvientes & 28,57 & 22,2 & 85,71 \\
\hline Elites & 100 & 100 & 100 \\
\hline$*$ & 59,42 & 75 & 72,09 \\
\hline TOTAL & $\mathbf{6 8 , 9 3}$ & $\mathbf{6 0 , 3 6}$ & $\mathbf{8 3 , 2 7}$ \\
\hline
\end{tabular}

Fuente: elaboración propia a partir de los padrones.

Por el contrario, las tasas de alfabetización de labradores y jornaleros eran más bajas en todos los casos. En los municipios alaveses del Alto Nervión los jornaleros se encontraban mejor preparados que los 
labradores; los de Amurrio estaban incluso más alfabetizados que sus homólogos de Urduña/Orduña. En todo caso, la de los jornaleros no es una categoría muy numerosa y en la misma parecen englobarse tanto trabajadores de pequeñas factorías, que eran escasas, como jornaleros agrícolas. Téngase en cuenta que en Amurrio solo el 5,24\% de la población total figura como jornalera frente al 30,17\% de labradores; en las otras localidades la proporción de jornaleros era aún menor, el 4,52\% en Urduña/Orduña y el 2,84\% en Laudio/Llodio.

En lo que respecta al resto de categorías, el número de sus integrantes es demasiado bajo como para extraer alguna conclusión. Únicamente podemos señalar el bajo nivel de formación de los escasos sirvientes masculinos que encontramos en Amurrio y Laudio/Llodio, y también apuntar el hecho de que no todos los escolares figuran como alfabetizados, lo que es especialmente habitual en Laudio/Llodio. Ello se debe a que era frecuente que aquellos que se encontraban aún en los primeros años de escolarización figurasen como analfabetos.

En cuanto a las mujeres, exceptuando a las que desempeñaban alguna profesión liberal, alfabetizadas en su totalidad pero poco relevantes numéricamente, las mejor preparadas eran, en general, las dedicadas al sector servicios. Es lo que ocurre en Laudio/Llodio y Urduña/ Orduña, pero en Amurrio este sector apenas alcanzaba un 66,67\% de alfabetización y eran las sirvientas domésticas las mejor preparadas. Las domésticas presentaban unas tasas altas también en el municipio vizcaíno, pero en Laudio/Llodio se quedaban en un 25\%. La razón puede residir en que, bajo la categoría de domésticas, se encuadraban dos perfiles distintos de sirvientas: las ligadas a familias de clase media y élites, más vinculadas al mundo urbano propio de Urduña/Orduña, y las domésticas propias del medio rural, que servían en casas de manera temporal.

Lo cierto es que en Laudio/Llodio las tasas de alfabetización femenina eran muy bajas en general, por lo que todos los sectores profesionales se encontraban en una clara desventaja respecto a las tasas de sus homólogas de los otros dos municipios. Por su parte, en Amurrio y Urduña/ Orduña jornaleras y labradoras presentaban tasas incluso inferiores a las de las amas de casa. De hecho, en Amurrio éstas eran las más alfabetizadas junto a las dedicadas al sector servicios. 
Cuadro 4. Alfabetización de las mujeres mayores de 10 años según actividad profesional (1890/1900) $(\%)$

\begin{tabular}{|l|c|c|c|}
\hline & Amurrio & Laudio/Llodio & Urduña/Orduña \\
\hline Amas de Casa & 63,54 & 31,9 & 62,73 \\
\hline Artesanos & 100 & 0 & 71,43 \\
\hline Escolares & 80 & 61,9 & 73,61 \\
\hline Estudiantes & 0 & 0 & 100 \\
\hline Jornaleros & 23,53 & 33,3 & 42,31 \\
\hline Jubilados & 0 & 0 & 100 \\
\hline Labradores & 42,95 & 24,4 & 52,38 \\
\hline Liberales & 100 & 100 & 100 \\
\hline Pobres & 50 & 0 & 50 \\
\hline Servicios & 66,67 & 100 & 100 \\
\hline Sirvientes & 100 & 24 & 84,85 \\
\hline$*$ & 53,91 & 0 & 65,52 \\
\hline TOTAL & $\mathbf{5 3 , 3 6}$ & $\mathbf{3 5}$ & $\mathbf{6 5 , 4 5}$ \\
\hline
\end{tabular}

Fuente: elaboración propia a partir de los padrones.

\section{Diferencias según procedencia}

Cabe plantearnos una última cuestión. Además de la desigual oferta educativa en las distintas localidades, ¿jugaba la procedencia de los individuos un papel relevante en los niveles de alfabetización total de la población? ¿Estaban los inmigrantes mejorando el capital humano de la comarca? Sabemos que, en el año 1900, los inmigrantes tenían tasas de alfabetización mayores que los nativos en Bizkaia y Gipuzkoa. De hecho, en la Gipuzkoa urbana la diferencia era nada menos que de unos 25 puntos porcentuales entre unos y otros, tanto en los hombres como en las mujeres. No ocurría lo mismo en Araba/Álava, «donde la cualificación y la formación no eran criterios de selección a la hora de desplazarse» ${ }^{52} \mathrm{y}$,

52 García, Pareja y Zarraga, «¿Sabe leer? ¿Sabe escribir?», 45. 
por lo tanto, los nativos aventajaban a los inmigrantes en materia alfabetizadora. ¿A cuál de estas realidades se ajustaba el Alto Nervión?

En estos momentos, la mayoría de la población de las tres localidades procedía del entorno geográfico más inmediato, que, según el caso, abarcaba una zona entre las provincias de Araba/Álava y Bizkaia. Los que procedían de allende estos lugares, como Gipuzkoa, Burgos o de ámbitos más lejanos como Madrid, son los que consideramos como inmigrantes propiamente dichos y eran cuantitativamente escasos: en Amurrio representaban el 7,14\% de la población total y en Laudio/Llodio un exiguo $2,19 \%$. Pero los datos de los padrones no ofrecen duda al respecto: los inmigrantes estaban notoriamente más preparados que los nativos del Alto Nervión. En este sentido, se aprecia un comportamiento diametralmente opuesto al alavés, si bien es verdad que las tasas de alfabetización de esta comarca eran inferiores a las de Araba/Álava.

Cuadro 5. Tasas de alfabetización según procedencia (1890/1900) (\%)

\begin{tabular}{|l|c|c|}
\hline & Inmigrantes & Nativos \\
\hline Amurrio & 83,33 & 58,46 \\
\hline Laudio/Llodio & 70 & 49,07 \\
\hline Urduña/Orduña & 76,79 & 74,62 \\
\hline
\end{tabular}

Fuente: elaboración propia a partir de los padrones.

En todo caso, nuevamente existen diferencias entre los tres municipios. Urduña/Orduña se ajusta perfectamente al modelo propio de la Bizkaia urbana, en el que la diferencia a favor de los inmigrantes es ligera, solamente de dos puntos porcentuales, debido a que las tasas de los nativos son elevadas de por sí. Por el contrario, en Amurrio y Laudio/ Llodio había una diferencia que superaba los 20 puntos porcentuales, por lo que se aproximaban al modelo de las villas guipuzcoanas.

Por lo tanto, no cabe duda de que el colectivo inmigrante asentado en el Alto Nervión, si bien escaso, contribuyó a elevar las tasas de alfabetización de la comarca. Las gentes que se instalaban en este lugar tenían ya una cierta formación, lo cual es indicativo de que se había producido una selección del personal emigrante en sus lugares de 
origen. No emigraba cualquiera sino aquellos mejor preparados o, al menos, suficientemente formados para contar con cierta ventaja frente a la población local. Además, hay que tener en cuenta que la mayoría de los inmigrantes procedían de la provincia de Burgos y especialmente de su parte norte, la más próxima al Alto Nervión. En esta área, la alfabetización también era alta de por sí, ${ }^{53}$ posiblemente fomentada por las instituciones locales y las mismas familias en el marco de unas estrategias cuyos objetivos eran idénticos o similares a los que alentaban el sistema educativo alavés y del Alto Nervión: la formación de cara a la emigración, el servicio en la administración y en puestos cualificados, etc.

A priori podría resultar llamativo que sean los inmigrantes asentados en Amurrio los que tenían una mayor tasa de alfabetización, pero no lo es tanto si tenemos en cuenta que esta localidad era cabeza de partido judicial y en ella residían no pocos profesionales liberales y funcionarios llegados de fuera. Es decir, personas con una preparación académica elevada y una especial cualificación.

También resulta llamativo que vizcaínos y alaveses tuvieran unas tasas tan distintas en cada una de las localidades. ¿Por qué los vizcaínos asentados en Laudio/Llodio estaban mucho menos alfabetizados que los instalados en Amurrio? ¿Por qué los alaveses que residían en Urduña/ Orduña tenían tasas más altas que los que pasaron a residir en Amurrio? Pensamos que la causa reside en la distancia de estas localidades respecto a Bizkaia y en la existencia de redes jerarquizadas. Es decir, los vizcaínos que se instalaron en Laudio/Llodio procedían de zonas rurales muy cercanas que están dentro de su ámbito de influencia inmediato; sin embargo, los que recalaban en Urduña/Orduña realizaban un desplazamiento más largo y, generalmente, con otro tipo de objetivos. ¿Sirve esta explicación para el caso alavés, si tanto Urduña/Orduña como Amurrio se alimentaban prácticamente de las mismas localidades alavesas? Posiblemente aquí entre en juego otro factor: la selección de los emigrantes en el lugar de origen. Es decir, el municipio vizcaíno sería el punto de recepción de población mejor formada, mientras que en los otros dos

\footnotetext{
${ }_{53}$ Rocío García Abad, «Alfabetización y capital humano inmigrante. Análisis diferencial de los niveles educativos de la población inmigrante en la primera industrialización vizcaína», Vasconia 38 (2012): 754.
} 
casos la formación no sería un criterio de selección, como hemos apuntado anteriormente para la provincia de Araba/Álava.

Hemos visto cómo en materia alfabetizadora existía una clara jerarquización espacial, por género, profesional y por procedencia. A pesar de su reducido tamaño, las diferencias entre localidades eran notables (y también dentro de ellas entre las zonas más dinámicas y las más ruralizadas), oscilando entre las altas tasas de Urduña/Orduña, situada a la cabeza del proceso alfabetizador vizcaíno, y las muy bajas de Laudio/ Llodio, por debajo de la media provincial vizcaína, a cuya realidad se aproxima más que a la alavesa.

No consideramos que la pertenencia jurisdiccional de Urduña/Orduña a Bizkaia marcase la diferencia respecto a sus vecinos alaveses. Habría sido la concentración de población, así como su mayor potencial económico, lo que favoreció el avance de la alfabetización, ya que siempre hubo centros escolares en ella. Con frecuencia, las concentraciones urbanas fueron los únicos lugares donde el acceso a la educación era posible. Además, «estar alfabetizado no supone lo mismo en el campo que en la ciudad. En ésta, la educación se convertía en requisito imprescindible cara a formar parte de los mercados de trabajo, por el tipo de ocupación profesional a desempeñar o por las propias necesidades de la vida urbana» ${ }^{54}$ Pero también hay que tener en cuenta los esfuerzos realizados por las autoridades municipales y provinciales, y por los padres de familia, para educar a los jóvenes. Ello se refleja en la larga tradición alfabetizadora existente en Urduña/Orduña. En Laudio/Llodio, solamente hacia 1880, con el impulso del Marqués de Urquijo, la escolarización empezó a extenderse en este disperso valle donde, además, el euskera, que puede interpretarse como un obstáculo para una escolarización que siempre era en castellano, solo entonces había empezado a retroceder.

Las tasas de alfabetización también fluctuaban notablemente en función del género, incluso en Urduña/Orduña. Como hemos dicho, es un diferencial compartido con las provincias de Álava y Bizkaia, que viene motivado por unas excepcionalmente altas tasas de alfabetización masculina, sobre todo en el caso alavés. Ello es fruto del tradicional interés

\footnotetext{
${ }^{54}$ García, Pareja y Zarraga, «¿Sabe leer? ¿Sabe escribir?», 36.
} 
por la inversión en la educación de los varones con el fin de que contasen con las cualidades necesarias para prosperar fuera de la casa, y la desatención de una educación femenina que no se consideraba rentable debido a su limitada participación en el mercado laboral.

El mismo razonamiento subyace en las diferentes tasas de alfabetización en función de la actividad profesional. Y es que, independientemente del lugar y las categorías analizadas, las tasas más altas se corresponden con un perfil más aperturista de la estructura productiva: así, había mayor nivel de alfabetización en aquellos sectores que mostraban una mayor diversificación de actividades, y una mayor presencia de los sectores secundario y terciario rompiendo la hegemonía habitual del sector primario. Y, en consecuencia, son aquellos lugares en los que se asientan, y aquellos de los que proceden, los que presentan mayores tasas de alfabetización.

\section{EL LOGRO DE LA ALFABETIZACIÓN UNIVERSAL}

El analfabetismo fue uno de los principales problemas de España hasta bien entrado el siglo XX, una importante tara para su desarrollo que se debía, fundamentalmente, a la falta de financiación por parte del Estado. La transición de la alfabetización en España se puede definir como un proceso gradual, caracterizado por su tardío inicio, al menos respecto a las potencias europeas, así como por su lentitud y alargada extensión en el tiempo. Paulí Dávila Balsera divide el proceso en dos etapas: la primera abarcaría desde la década de los sesenta del siglo XIX hasta comienzos de la siguiente centuria, periodo en el que desaparece el modelo de semialfabetización anterior y se reducen las diferencias entre las tasas de ambos sexos, aunque apenas se alcanzó el primer umbral de alfabetización, en torno al 30-40\% de población alfabeta. ${ }^{55}$ La segunda etapa se alargaría aproximadamente hasta los inicios del franquismo, periodo en el que los cambios sociales, económicos y demográficos fueron paralelos al descenso del analfabetismo. La alfabetización universal no se alcanzaría hasta la segunda mitad de siglo.

${ }_{55}$ García, Pareja y Zarraga, «¿Sabe leer? ¿Sabe escribir?», 71. 
Sin embargo, la situación en las provincias vascas no se corresponde con lo ocurrido en la mayor parte de España, y lo mismo podemos decir del Alto Nervión. Ya en el periodo anteriormente analizado mostraba un perfil más avanzado en materia educativa, si bien no tanto como la totalidad de la provincia de Araba/Álava. Pero serán precisamente las décadas anteriores a la Guerra Civil las que asistan a la consecución de la alfabetización universal, tanto por parte del Alto Nervión como del País Vasco en general. Así, en 1930, Araba/Álava era la provincia con mayor tasa de alfabetización del Estado con un 90\%. Por su parte, tanto Bizkaia como Gipuzkoa habían alcanzado ya una tasa del $86 \%$, mientras que la media estatal no ascendía más que al 68\%.56 Se trata de unas tasas acordes con el nivel de desarrollo económico alcanzado por las provincias costeras y por ello es tan reseñable que un territorio tan tímida y localmente modernizado como Álava se situara en cabeza.

Para analizar el logro de la alfabetización universal haremos uso de los padrones de población de los tres municipios mencionados correspondientes al año 1935. Tampoco esta vez haremos referencia a aquellas personas en estado de semialfabetización, y con mayor motivo, puesto que en el conjunto de los padrones únicamente aparecen cuatro personas en situación de semialfabetización. En consecuencia, la diferencia entre alfabetismo y semialfabetismo era estadísticamente nula.

En lo que respecta a la situación económica del Alto Nervión en vísperas de la Guerra Civil, en los diez años anteriores se había producido un primer impulso industrial limitado, pero con la capacidad suficiente para atraer población inmigrante e incrementar sus censos demográficos. Esto ocurrió sobre todo en Amurrio, cuya población creció un $72,54 \%$ hasta situarse en 1.910 habitantes, y en Laudio/Llodio, que incrementó su población en un 18,65\% hasta alcanzar los 2.379 habitantes. Mientras, la vizcaína Urduña/Orduña continuaba siendo sobre todo un centro comercial y artesanal orientado a un mercado estrictamente comarcal. ${ }^{57}$ Eso sí, aún era la localidad más poblada con 3.394 vecinos.

\footnotetext{
56 Ostolaza, Entre religión y modernidad, 51.

57 Merino, «El Alto Nervión», 99-102.
} 
Cuadro 6. Alfabetización por municipios y género, mayores de 10 años (1935)

\begin{tabular}{|l|l|c|c|}
\hline & & \multicolumn{2}{|c|}{ Leer y escribir } \\
\hline & & $\mathbf{n}^{\mathbf{0}}$ & $\%$ \\
\hline Amurrio & Hombres & 621 & 87,96 \\
\hline & Mujeres & 632 & 82,61 \\
\hline & TOTAL & $\mathbf{1 2 5 3}$ & $\mathbf{8 5 , 1 8}$ \\
\hline Laudio/Llodio & Hombres & 906 & 97,21 \\
\hline Urduña/Orduña & Mujeres & 954 & 94,27 \\
\hline & TOTAL & $\mathbf{1 8 6 0}$ & $\mathbf{9 5 , 6 8}$ \\
\hline & Hombres & 1260 & 98,51 \\
\hline Alto Nervión & Mujeres & 1392 & 94,76 \\
\hline & TOTAL & $\mathbf{2 6 5 2}$ & $\mathbf{9 6 , 5 1}$ \\
\hline & Hombres & 2787 & 95,54 \\
\hline & Mujeres & 2978 & 91,74 \\
\hline & TOTAL & $\mathbf{5 7 6 5}$ & $\mathbf{9 3 , 5 4}$ \\
\hline
\end{tabular}

Fuente: elaboración propia a partir de los padrones.

Si hay algo que se deduce con claridad del cuadro 6 es que el avance en materia educativa desde los años finales de la centuria anterior fue más que notable, de modo que en 1935 la alfabetización universal ya era una realidad. Las tasas eran tan elevadas que el analfabetismo había quedado reducido a una pequeña minoría prácticamente insignificante. En el conjunto de la comarca se alcanzó un nivel de alfabetización del 93,54\%, superando tanto Urduña/Orduña como Laudio/Llodio esa cifra. Era Amurrio la que mostraba una tasa netamente inferior, del $85,18 \%$, fruto de una serie de circunstancias de difícil interpretación, como veremos. En todo caso, el avance fue espectacular y produjo la convergencia de las cifras tanto de la provincia de Araba/Álava como la de Bizkaia y el País Vasco en su conjunto. Ello queda reflejado en el cuadro 7 . 
Cuadro 7. Evolución de la alfabetización en el País Vasco, 1877-1930 ( $\geq 10$ años) (\%)

\begin{tabular}{|l|c|c|c|c|c|}
\hline & Araba/Álava & Bizkaia & Gipuzkoa & País Vasco & España \\
\hline 1877 & 56,4 & 45,6 & 35,8 & 45,6 & 30 \\
\hline 1900 & 73,3 & 62,5 & 53,7 & 61,2 & 47 \\
\hline 1930 & 89,2 & 86,1 & 86 & 86,4 & 68 \\
\hline
\end{tabular}

Fuente: Manuel González Portilla, José Urrutikoetxea Lizarraga y Karmele Zarraga Sangroniz, «Ferrocarril, urbanismo y capital humano: los "procesos vascos" de modernización (1876-1930)», en Ferrocarriles y sociedad urbana en el País Vasco, ed. Pedro Novo López (Leioa, Universidad del País Vasco, 2014): 42-56.

\section{Superando obstáculos, eliminando diferencias}

El avance alfabetizador en el primer tercio del siglo XX en el Alto Nervión fue muy importante en un doble sentido. Primero, en lo territorial, puesto que la localidad de Laudio/Llodio fue capaz de recortar la enorme distancia que le separaba de Urduña/Orduña y lograr tasas de alfabetización similares en un intervalo inferior a los 40 años. Sin duda, la actividad benéfica de los marqueses de Urquijo debió ejercer una influencia notable en la consecución de la alfabetización universal. Sus escuelas de Patronato pasaron a estar regidas por órdenes religiosas: desde 1922 las Hermanas de la Caridad de San Vicente de Paul estaban a cargo de la educación femenina y en 1931 los Hermanos de Mené pasaron a controlar la educación masculina. Por otro lado, en 1926 y 1928 entraron en funcionamiento las escuelas mixtas de los barrios de Areta y Gardea, respectivamente. Finalmente, en 1930 se puso en marcha la Escuela de Artes y Oficios, de acuerdo con el progresivo incremento de la necesidad de mano de obra más cualificada y especializada. ${ }^{58}$

La mejora de las infraestructuras facilitó el proceso alfabetizador pero, obviamente, el éxito solo pudo lograrse mediante la superación de aquellos otros obstáculos que décadas atrás dificultaban la alfabetización de la totalidad de los jóvenes. Para ello fue necesario, sobre todo,

\footnotetext{
58 Juan José Salazar Olabarria y Javier Salcedo Eguía, Recuperación de la memoria colectiva: Laudio-Llodio (Laudio/Llodio: Fundación Amalur, 2007), 279.
} 
voluntad: para superar la distancia que les separaba de las escuelas, para liberar a los niños del trabajo en la casa y los negocios familiares, etc. El funcionamiento de escuelas nocturnas y para adultos es el mejor reflejo del interés general de la población por alfabetizarse.

En segundo lugar, si a finales del siglo XIX el diferencial sexual estaba muy acentuado, en puertas de la Guerra Civil se había conseguido reducirlo al mínimo. Los hombres aún mostraban unas tasas de alfabetización superiores a las mujeres en unos tres o cuatro puntos porcentuales, pero obviamente la situación ya no tenía nada que ver con la propia de la centuria anterior. La conclusión es, en definitiva, que la práctica totalidad de la población sabía al menos leer y escribir salvo algunos casos excepcionales y muy minoritarios.

Sin embargo, en 1935 Amurrio no había logrado alcanzar unas tasas tan elevadas como los otros municipios, quedándose unos diez puntos por debajo, en el $85,18 \%$, y ello a pesar de que partía con ventaja respecto al municipio vecino. Es un dato llamativo teniendo en cuenta además que Amurrio fue la localidad que mayor crecimiento demográfico experimentó en este periodo y el que más se industrializó. ${ }^{59}$ Es cierto que las mujeres también habían reducido notablemente la ventaja de los hombres, pero, ¿cuál es la razón por la cual Amurrio no consiguió avanzar en el campo de la instrucción tanto como lo hizo Laudio/Llodio a pesar de su mayor desarrollo?

Es cierto que la diferencia con esta localidad en cuanto a calidad de las infraestructuras educativas era notable. Las nuevas escuelas de Amurrio no se inauguraron hasta 1905, cuando por fin sustituyeron a la vieja casa en la que se venía impartiendo la docencia. Además, los problemas en las aulas se agravaban debido a la escasa dotación para el maestro, la falta de materiales didácticos adecuados y la irregular asistencia del alumnado debido a su empleo en las tareas agrícolas y domésticas. ${ }^{60} \mathrm{De}$ todos modos, la situación fue mejorando con el tiempo y también se creó una escuela específica para las niñas. En 1922 se creó un parvulario con capacidad para 40 alumnas a cargo de las Hermanas Terciarias Capuchinas.

\footnotetext{
59 Merino, «El Alto Nervión», 95.

60 Javier Aspuru Oribe, «Amurrioko udaletxearen 100 urteurrena », Aztarna 29 (2005): 32-40.
} 
Finalmente, la separación de los alumnos por edades en distintas aulas no se produjo hasta la llegada de la II República: en 1935 se inauguraron las nuevas escuelas costeadas por la Diputación Foral de Ála$v^{6}{ }^{61}$. En resumen, es posible que estas condiciones, menos favorables que en Laudio/Llodio, provocaran la mayor lentitud del proceso alfabetizador en la localidad. Pero, en todo caso, pueden ser otros los factores que expliquen las más bajas tasas de alfabetización que presentaba Amurrio en 1935 respecto a sus municipios vecinos.

Cuadro 8. Alfabetización por tramos de edad, mayores de 10 años (1935) (\%)

\begin{tabular}{|l|c|c|c|}
\hline & Amurrio & Laudio/Llodio & Urduña/Orduña \\
\hline $10-14$ & 78,82 & 97,77 & 99,1 \\
\hline $15-19$ & 88,37 & 99,14 & 99,7 \\
\hline $20-24$ & 89,29 & 99,1 & 99,11 \\
\hline $25-29$ & 89,2 & 100 & 99,57 \\
\hline $30-34$ & 88,11 & 98,93 & 98,76 \\
\hline $35-39$ & 85,5 & 97,04 & 97,37 \\
\hline $40-44$ & 89,66 & 96 & 97,84 \\
\hline $45-49$ & 87,95 & 97,27 & 95,24 \\
\hline $50-54$ & 83,75 & 97 & 94,66 \\
\hline $55-59$ & 92,73 & 90,59 & 93,62 \\
\hline $60-64$ & 84,91 & 90,91 & 92,44 \\
\hline $65-69$ & 81,25 & 94,37 & 86,46 \\
\hline $70-74$ & 62,5 & 76,47 & 88,04 \\
\hline $75-79$ & 70 & 74,42 & 82,69 \\
\hline$>=80$ & 45 & 56,67 & 85,45 \\
\hline
\end{tabular}

Fuente: elaboración propia a partir de los padrones.

${ }_{61}$ Aztarna, Amurrio 1900-1950: un paseo por el pueblo de nuestros abuelos a través de la fotografía. (Amurrio: Aztarna, 2007), 76-82. 
El cuadro 8 muestra que en Amurrio las tasas de alfabetización eran inferiores a las de las otras localidades en la gran mayoría de las franjas de edad. En los otros dos municipios, los escasos analfabetos se concentraban en edades muy avanzadas, sobre todo entre los mayores de 70 años, mientras los menores de 30 estaban alfabetizados en su práctica totalidad. La alfabetización universal se habría logrado, por tanto, a principios de siglo. Sin embargo, Amurrio no solo se encontraba siempre ligeramente por debajo de sus vecinos, sino que incluso experimentó un muy llamativo descenso entre los diez y los catorce años de edad, que es precisamente la franja que presentaba menor porcentaje de alfabetizados, solo por detrás de los mayores de 70 años. Más aún, la franja de edad con mayor porcentaje de alfabetos era la de aquellos nacidos entre 1875 y 1880. ¿Cuál es la razón que explica el descenso de las tasas precisamente en aquellos que, siguiendo la lógica de los municipios vecinos, deberían estar alfabetizados en su totalidad? ¿Por qué Amurrio no consigue alcanzar en ninguna franja de edad tasas del $90 \%$ de alfabetizados?

\section{Diferencias socioprofesionales}

Quizá la explicación a este hecho esté relacionada con las divergencias que se observan en las localidades en función de su estructura productiva. A este respecto, en 1935 en Laudio/Llodio y Urduña/Orduña los analfabetos constituían unos pocos casos aislados y todas las categorías profesionales presentaban tasas de alfabetización muy elevadas, del 100\% en muchos casos. Labradores y amas de casa eran las categorías en las cuales aparecía mayor número de analfabetos, pero en muy bajas cantidades.

En cambio, la situación no era la misma en Amurrio. En lo que respecta a los varones, artesanos, empleados en el sector terciario y, por supuesto, a las élites y los estudiantes, la alfabetización alcanzaba prácticamente a su totalidad. Sin embargo, había varias categorías profesionales que se encontraban en una posición menos favorable: eran los labradores y jornaleros, con tasas del $83,75 \%$ y 90,7\%, respectivamente. En lo que respecta a las mujeres, las menos alfabetizadas eran las labradoras y, especialmente, las amas de casa.

Incluso por debajo de éstos se hallaban los escolares, alfabetizados solo el $81,16 \%$ de los hombres y el 73,91\% de las mujeres. Parece ser que, a la hora de elaborar el padrón, no se acreditó la capacidad de leer y escribir a 
jóvenes que aún no habían finalizado los estudios. Este particular criterio a la hora de clasificar a la población explicaría las bajas tasas de alfabetización del grupo de edad comprendido entre los 10 y los 14 años, lo que habría contribuido a mantener las tasas totales de la localidad en un nivel más bajo que, por ejemplo, el del municipio de Laudio/Llodio. Pero no explican en absoluto las bajas tasas de los labradores y jornaleros.

\section{Diferencias según procedencia}

Por otro lado, ¿siguió jugando la inmigración el mismo papel que desempeñaba en la década final del siglo XIX? ¿Tuvo alguna relación con el avance de la alfabetización en general y con el retraso de Amurrio en particular? En primer lugar, tampoco en 1935 existía un comportamiento homogéneo al respecto en el Alto Nervión. Si en el periodo anterior, en los municipios alaveses los inmigrantes estaban más alfabetizados que los nativos, en esta ocasión tal circunstancia solo ocurría en Laudio/Llodio y por una mínima diferencia, ya que la alfabetización era prácticamente generalizada. En Amurrio, por el contrario, eran precisamente los inmigrantes los menos alfabetizados de todos y eran los vizcaínos quienes se situaban a la cabeza. Nada sorprendente, puesto que llegaron a la localidad muchos individuos procedentes de Bilbao y alrededores como técnicos y empleados de las empresas que se instalaron en ella, es decir, a ocupar puestos de trabajo cualificados. ${ }^{62}$ Por su parte, en Urduña/Orduña eran los nativos los más alfabetizados, pero todos los grupos presentaban tasas muy elevadas.

En Urduña/Orduña y Laudio/Llodio los alaveses eran los menos alfabetizados, ya que la mayoría procedía de los municipios rurales colindantes, en los que todavía existían ciertos frenos a la generalización de la escolarización. También en Amurrio aquellos colectivos se encontraban en un nivel inferior a los nativos y los vizcaínos, si bien por encima de los inmigrantes. En general, el avance de la alfabetización se debió sobre todo al esfuerzo de los nativos, que en determinados casos consiguieron incluso superar los niveles de formación de los inmigrantes. Es lo mismo que ocurrió en la Bizkaia urbana e incluso la Gipuzkoa urbana estaba a punto de conseguirlo en este momento. ${ }^{63}$

\footnotetext{
${ }^{62}$ Merino, «El Alto Nervión», 58.

${ }^{63}$ García, Pareja y Zarraga, «¿Sabe leer? ¿Sabe escribir?», 70.
} 
En todo caso, es Amurrio la que llama nuevamente nuestra atención. Todos los colectivos, tanto nativos como alaveses, vizcaínos e inmigrantes, tenían tasas de alfabetización menores que sus homólogos de los municipios vecinos. La decisión de no clasificar como alfabetizados a todos los escolares no explica este fenómeno por sí solo, como tampoco lo explica una posible desventaja en la oferta educativa. Tampoco creemos que se trate de una cuestión de menor desarrollo socioeconómico, ya que, como hemos señalado, Amurrio había crecido en mayor medida y proporción que Laudio/Llodio y Urduña/Orduña. ¿A qué se debe entonces esta diferencia de Amurrio en sus tasas de alfabetización? ¿Es acaso una cuestión que radica únicamente en las fuentes mismas y los criterios empleados para clasificar a la población? Puede ser que, a la hora de elaborar el padrón de Amurrio, se emplearan criterios distintos al considerar qué es estar alfabetizado y qué no; por ejemplo, en unos casos se pudo considerar que el semialfabetismo era una forma efectiva de alfabetización, pero no así en Amurrio.

\section{En resumen}

En todo caso, a pesar de las preguntas que nos suscita el extraño caso de Amurrio, el hecho fundamental en 1935 es que el Alto Nervión había conseguido alcanzar la alfabetización universal, tanto para los hombres como para las mujeres. Lo hizo además de manera notoria, relegando los casos de analfabetismo a la categoría de mera anécdota, y situándose en tasas realmente elevadas incluso dentro del ya muy desarrollado contexto vasco. Y, paralelamente, se había puesto en marcha un primer y tímido proceso de industrialización que tuvo lugar en los municipios alaveses y especialmente en Amurrio a partir de 1926. Para entonces, el Alto Nervión ya había superado el segundo umbral de alfabetización y contaría con una población lo suficientemente preparada para afrontar el reto modernizador con ciertas garantías de éxito.

\section{CONCLUSIONES}

El presente trabajo constituye un estudio de caso que ayuda a la comprensión de un fenómeno como el alfabetizador en el que es necesario prestar atención a los matices y huir de generalizaciones, ya que, 
como hemos visto, ni el País Vasco, ni Álava, ni siquiera el Alto Nervión, tienen comportamientos homogéneos y son varios los factores que influyen en su proceso de alfabetización. Las diferencias territoriales, de género, socioprofesionales y en función del lugar de origen eran características en la comarca a finales del siglo XIX, a pesar de tener una trayectoria pasada bastante proclive al fomento de la educación. En un lugar donde la inmigración fue un recurso básico para el progreso del individuo y su familia, la enseñanza siempre fue una cuestión de importancia. ${ }^{64}$

Gracias a los esfuerzos de algunos benefactores como el Marqués de Urquijo en el caso de Laudio/Llodio, y de las autoridades locales en general, y sobre todo al convencimiento de la necesidad de la educación por parte de los propios cabezas de familia, todos los obstáculos que se oponían al acceso generalizado a la enseñanza básica fueron superados, y la comarca ya estaba universalmente alfabetizada en 1935. Probablemente, este logro era ya una realidad un par de décadas antes. En este sentido, el Alto Nervión se ajusta al comportamiento medio del conjunto de las provincias vascas, claramente más precoz que el conjunto de España.

La superación de los dos umbrales de alfabetización definidos por Bowman y Anderson, claro está, no se tradujo en la inmediata puesta en marcha de un proceso modernizador, ya que en ello influyen de manera decisiva otro tipo de condicionantes y elementos. Pero no deja de ser cierto que el logro de la alfabetización universal se produjo al mismo tiempo, probablemente con algo de antelación, a la puesta en marcha de un primer proceso de industrialización en la comarca. Por lo tanto, el logro de unas altas tasas de alfabetización no lleva de manera directa a la modernización, pero sí parece ser un elemento indispensable para ello, ya que constituye una mejora en un capital humano que, al poseer esas cualidades positivas, resulta competitivo en un contexto en el que las capacidades de los trabajadores también se toman en consideración como factor de modernización.

\footnotetext{
${ }^{64}$ Rocío García Abad, Historias de emigración. Factores de Expulsión y Selección de capital humano en la emigración a la Ría de Bilbao (1876-1935) (Bilbao: Servicio Editorial de la UPV/EHU, 2005), 113-114.
} 


\section{Nota sobre el autor}

Aketza Merino Zulueta es doctor en Historia Contemporánea por la Universidad del País Vasco con su tesis sobre el proceso de cambio de la comarca vasca del Alto Nervión en el contexto de las modernizaciones vascas, defendida en julio de 2017. Fruto de este proyecto de investigación, son diversos artículos publicados en revistas especializadas que tratan sobre los movimientos migratorios en el entorno de Bilbao a mediados del siglo XX o la crisis de la sociedad agraria alavesa a finales del siglo XIX. Es autor así mismo de investigaciones en torno a la evolución y desaparición del euskera en el norte de Álava. Ha publicado un libro titulado 15 años sobre las guerras decimonónicas en el Alto Nervión, y colabora con diversos medios de divulgación histórica en euskera y castellano.

\section{REFERENCIAS}

Aspuru Oribe, Javier. "Amurrioko udaletxearen 100 urteurrena». Aztarna 29 (2005): 32-40.

Aztarna. Amurrio 1900-1950: un paseo por el pueblo de nuestros abuelos a través de la fotografía. Amurrio: Aztarna, 2007.

Becerro de Bengoa, Ricardo. La enseñanza en el siglo XX. Madrid: Ed. Edmundo Capdeville, 2009.

Bowman, Mary Jane y C. Arnold Anderson. "Concerning the Role of Education in Development». En Old Societies and New States, editado por Clifford Geertz, 247-269. Glencoe: The Free Press, 1963.

Capellán de Miguel, Gonzalo. Ricardo Becerro de Bengoa. La enseñanza en el siglo XX. Leioa: Servicio Editorial de la UPV/EHU, 2001.

Carreras Candi, Francesc. Geografía general del País Vasco. Bilbao: La Gran Enciclopedia Vasca, 1980.

Collantes Gutiérrez, Fernando. "¿Fue el capital humano importante para la diversificación económica de la España rural (1950-1991)?». Revista de Demografía Histórica 25, no. 1 (2007): 165-190.

Dávila Balsera, Paulí. La política educativa y la enseñanza pública en el País Vasco (1860-1930). San Sebastián: Ibaeta Pedagogía, 1995.

García Abad, Rocío. "Alfabetización y capital humano inmigrante. Análisis diferencial de los niveles educativos de la población inmigrante en la primera industrialización vizcaína». Vasconia 38 (2012): 741-759.

García Abad, Rocío. Historias de emigración. Factores de Expulsión y Selección de capital humano en la emigración a la Ría de Bilbao (1876-1935). Bilbao: Servicio Editorial de la UPV/EHU, 2005. 
García Abad, Rocío, Arantza Pareja Alonso y Karmele Zarraga Sangroniz. «¿Sabe leer? ¿Sabe escribir? El proceso de alfabetización en el País Vasco». Revista de Demografía Histórica 25, no. 1 (2007): 25-38.

González Portilla, Manuel y José Urrutikoetxea Lizarraga. Vivir en familia, organizar la sociedad: familia y modelos familiares, las provincias vascas a las puertas de la modernización (1860). Bilbao: Servicio Editorial de la UPV-EHU, 2003.

González Portilla, Manuel, José Urrutikoetxea Lizarraga y Karmele Zarraga Sangroniz. La "otra industrialización» del País Vasco: las pequeñas y medianas ciudades: capital humano e innovación social durante la primera industrialización. Bilbao: Editorial UPV/EHU, 2015.

González Portilla, Manuel y José Urrutikoetxea Lizarraga. «El capital humano en la primera modernización industrial vasca (1876-1930). Viejas herencias e innovaciones recientes». Revista de Demografía Histórica 34, no. 2 (2016): 53-83.

Goody, Jack. Literacy in Traditional Societies. Cambridge, Cambridge University Press, 1968.

Ladrón de Guevara López de Arbina, Ernesto. La conformación del sistema educativo en Álava (1860-1936): centralización y foralismo. Vitoria-Gasteiz: Diputación Foral de Álava-Departamento de Cultura, 2000.

Luria, Aleksandr Románovich. Cognitive Development. Its Cultural and Social Foundations. Cambridge: Cambridge University Press, 1976.

Madoz, Pascual. Diccionario geográfico-estadístico-histórico. Álava. Valladolid: Ámbito, 1989.

Mendia, Santiago. El condado de Ayala. Vitoria-Gasteiz: Diputación Foral de Álava, 1994.

Merino Zulueta, Aketza. «El Alto Nervión: La cara oculta de la modernización vasca (1876-1936): otras funciones, otros ritmos». Trabajo de Fin de Máster, Universidad del País Vasco, 2011.

Mitch, David. «Educación y crecimiento económico: ¿Otro axioma de indispensabilidad? Del capital humano a las capacidades humanas». En La maldición divina. Ignorancia y atraso económico en perspectiva histórica, editado por Clara Eugenia Núñez y Gabriel Tortella, 41-60. Madrid: Alianza Universal, 1993.

Núñez, Clara Eugenia. La fuente de la riqueza. Educación y desarrollo económico en la España contemporánea. Madrid: Alianza, 1992.

Núñez, Clara Eugenia y Gabriel Tortella (eds.). La maldición divina. Ignorancia y atraso histórico en perspectiva histórica. Madrid: Alianza, 1993.

Ormaetxea Garai, Xabier. «Ramón Ortiz de Zárate Martínez de Galarreta (18171883). Biografía político-institucional y análisis político de su figura u obra entre 1840 y 1858». Trabajo de Fin de Máster, Universidad del País Vasco, 2011. 
Ostolaza Esnal, Maitane. Entre religión y modernidad: los colegios de las congregaciones religiosas en la construcción de la sociedad guipuzcoana contemporánea: 1876-1931. Bilbao: UPV-EHU, 2000.

Pollard, Sidney Pollard. Peaceful Conquest: The Industrialization of Europe 1760-1970. Oxford: Oxford University Press, 1982.

Reboredo Olivenza, José Daniel. «La organización administrativa de la primera enseñanza decimonónica (1825-1930)». Sancho el Sabio 5 (1995): 307-322.

Salazar Olabarria, Juan José y Javier Salcedo Eguía. Recuperación de la memoria colectiva: Laudio-Llodio. Laudio/Llodio: Fundación Amalur, 2007.

Sandberg, L. G. Sandberg. «Ignorance, poverty and economic backwardness in the early stages of European industrialization: variations on Alexander Gerschenkron's grand theme». Journal of European Economic History 11, no. 3 (1982): 675-697.

Schultz, Theodore William. «The value on the ability to deal with disequilibria». Journal of Economic History 39, no. 3 (1975): 827-846.

Schultz, Theodore William. Investing in People. The Economics of Population Quality. Berkeley: University of California Press, 1981.

Solow, Robert. «Technical Change and the Aggregate Production Function». Review of Economics and Statistics 39 (1957): 312-320. 